University of Nebraska - Lincoln

DigitalCommons@University of Nebraska - Lincoln

USDA National Wildlife Research Center - Staff Publications
U.S. Department of Agriculture: Animal and Plant Health Inspection Service

2009

\title{
Survival and Cause-Specific Mortality of Wild Turkeys in Northern Indiana
}

Lee A. Humberg

USDA Wildlife Services, Brooklyn, NY, humberg01@gmail.com

Travis L. Devault

USDA/APHIS/WS National Wildlife Research Center, Travis.L.DeVault@aphis.usda.gov

Olin E. Rhodes Jr.

Purdue University, rhodes@srel.uga.edu

Follow this and additional works at: https://digitalcommons.unl.edu/icwdm_usdanwrc

Part of the Environmental Sciences Commons

Humberg, Lee A.; Devault, Travis L.; and Rhodes, Olin E. Jr., "Survival and Cause-Specific Mortality of Wild Turkeys in Northern Indiana" (2009). USDA National Wildlife Research Center - Staff Publications. 845. https://digitalcommons.unl.edu/icwdm_usdanwrc/845

This Article is brought to you for free and open access by the U.S. Department of Agriculture: Animal and Plant Health Inspection Service at DigitalCommons@University of Nebraska - Lincoln. It has been accepted for inclusion in USDA National Wildlife Research Center - Staff Publications by an authorized administrator of DigitalCommons@University of Nebraska - Lincoln. 


\title{
Survival and Cause-Specific Mortality of Wild Turkeys in Northern Indiana
}

\author{
LEE A. HUMBERG, ${ }^{1}$ TRAVIS L. DEVAULT ${ }^{2}$ AND OLIN E. RHODES, JR. \\ Department of Forestry and Natural Resources, Purdue University, 195 Marsteller Street, \\ West Lafayette, Indiana 47907
}

\begin{abstract}
Information regarding survival and cause-specific mortality of eastern wild turkeys (Meleagris gallopavo silvestris) is vital to their management, especially in small or isolated populations. Between January 2003 and August 2005, we used radio telemetry to investigate survival and cause-specific mortality of 87 [44 male (24 adult and 20 juvenile) and 43 female (34 adult and 9 juvenile)] wild turkeys in northern Indiana. We estimated annual and seasonal survival using the Kaplan-Meier product-limit method. Mean male and female annual survival estimates were 0.257 and 0.777 , respectively. Annual survival estimates were different between sexes within years, but were homogenous within sexes between years. Survival estimates did not differ among seasons for either sex. However, differences in survival estimates between sexes were detected in the spring, fall and winter seasons. Hunter harvest ( $46.2 \%$ male mortality) and predation ( $33.3 \%$ female mortality) were the leading known causes of mortality for male and female wild turkeys, respectively. Predators (canids, birds and unknown mammals) were responsible for $28.6 \%$ of mortality for both sexes combined. Although predation on adult birds was not severe, high mortality of male turkeys in the form of legal spring harvest, in addition to other causes of mortality, warrants concern for small, exploited populations in highly fragmented landscapes like those of northern Indiana.
\end{abstract}

\section{INTRODUCTION}

Successful restoration of the eastern wild turkey (Meleagris gallopavo silvestris; hereafter, turkey) into the agricultural landscape of the Midwest has aided in range expansion of the species. For example, the number of turkeys in Indiana increased from $<1,000$ in 1970 to $>45,000$ in 1994, and occupied huntable range increased from $45 \mathrm{~km}^{2}$ to $36,129 \mathrm{~km}^{2}$ over the same period (Backs, 1995; Kennamer and Kennamer, 1995). Increases in the range occupied by turkeys and overall numbers of turkeys inhabiting midwestern landscapes have been accompanied by an increased interest in turkey hunting (Keck and Langston, 1992; Tapley et al., 2000). In the highly fragmented agricultural landscape of northern Indiana, the highest densities of turkeys often are associated with public lands, where managers of state properties have increased harvest opportunities to meet the rising demands of hunters (Backs, 1995). Thus, turkeys have reemerged as an important game species in Indiana and other midwestern states (Baumann et al., 1990), and the need for effective management of turkey populations by state agencies has become more pronounced (Kurzejeski et al., 1987).

Estimation of demographic parameters, such as survival rates and cause-specific mortality, is critical for development of efficient management strategies for turkeys (Healy and Powell, 2000). Although data on cause-specific mortality and survival are available for turkeys in several regions of the Midwest (Kurzejeski et al., 1987; Wright et al., 1996; Hubbard et al., 1999; Wright and Vangilder, 2000), none are available for turkey populations in Indiana. This lack of data warrants concern, given that Indiana has retained only $19 \%$ of its forest

\footnotetext{
${ }^{1}$ Corresponding author present address: United States Department of Agriculture, Wildlife Services, 1750 Pennsylvania Avenue, Brooklyn, New York 11239; e-mail: Lee.A.Humberg@aphis.usda.gov

${ }^{2}$ Present address: United States Department of Agriculture, Wildlife Services, National Wildlife Research Center, 6100 Columbus Avenue, Sandusky, Ohio 44870
} 
habitat and is one of the most rurally human-populated states in the Midwest (U.S. Census Bureau, 2000). Furthermore, Plowman (2004, 2006) reported that densities of mesopredators in Indiana are at or near all-time recorded highs. The limited forested habitat, dense human population and high predator densities found in Indiana make it critical that wildlife biologists and land managers have access to quantitative data on turkey survival and cause-specific mortality to assist them in management of this valuable wildlife species. As such, our objectives in this paper were to (1) determine cause-specific mortality of turkeys in northern Indiana, (2) estimate annual and seasonal survival rates for male and female turkeys and (3) compare intersexual estimates of wild turkey survival within and among years and seasons in northern Indiana.

\section{STUDy AREA}

This research was conducted within a 113,850 ha study area encompassing both public (state managed lands) and privately owned lands in portions of Huntington, Grant, Miami and Wabash Counties, Indiana. These counties were within the Upper Wabash River Basin (UWB) of northern Indiana (Moore and Swihart, 2005). Land ownership in the UWB was almost entirely private $(96 \%)$. Land use in the UWB was predominately row-crop agriculture (88\% corn [Zea mays] and soybean [Glycine max] production), and approximately $8 \%$ of the UWB was forested (Swihart and Slade, 2004). Most forest patches (75\%) in the UWB were $<5$ ha and the few relatively large forest tracts $(>100$ ha, $1 \%)$ were restricted to major drainages unsuitable for agriculture (Moore and Swihart, 2005). Forestland tree species composition was predominately a secondary growth oak (Quercus spp.) - hickory (Carya spp.) - maple (Acer spp.) mixture in the uplands and an ash (Fraxinus spp.) - elm (Ulmus spp.) - hackberry (Celtis occidentalis) - sycamore (Platanus occidentalis) mixture in the bottomlands. Elevation in the UWB averaged $243 \mathrm{~m}$ above sea level and topography was flat with gently rolling river drainages. Climate can be characterized as temperate with warm summers and cold winters. Precipitation varied with temperature and averaged $102 \mathrm{~cm}$ of rainfall and $81 \mathrm{~cm}$ of snowfall annually. The coldest month, January, averaged temperatures of $-4 \mathrm{C}$, whereas the warmest month, July, averaged $23 \mathrm{C}$. Snowfalls of $>16 \mathrm{~cm}$ rarely occurred more than once per year and accumulated snow depth rarely exceeded $25 \mathrm{~cm}$ (NOAA National Weather Service, 2005).

The study area was bounded on the western and eastern sides by the Mississinewa and Salamonie Reservoirs, respectively. These properties, which constitute nearly all the public land acreage in the study area, were Army Corp of Engineers flood control reservoirs managed by the Indiana Department of Natural Resources. The Mississinewa and Salamonie Reservoirs and their associated lands were approximately 1,775 ha and 5,033 ha in size, respectively. Each reservoir included approximately 350 tenant-leased agricultural fields ranging in size from 0.4 to 7.3 ha. Surrounding each reservoir were approximately 175 small ( $\sim 0.5$ ha) food plots (mainly corn, soybeans, sorghum [Sorghum spp.] and sunflower [Helianthus spp.]) that were planted for wildlife use. Privately owned lands in the study area were predominately farmlands with associated small woodlands. Average agricultural field size was 17 ha and $73 \%$ of all fields were $\leq 24$ ha.

\section{MethodS}

From January through March of 2003-2005 we captured turkeys using box-style rocket nets (Bailey et al., 1980). Capture sites $(\mathrm{n}=12)$ were partitioned throughout the study area on public and private lands to radiomark turkeys inhabiting areas of varying agriculture and forestland composition. Bait sites were placed in agricultural fields adjacent to woodlands 
where turkey sign (tracks, droppings or feathers) were present. Upon capture, all birds were removed from the net and placed individually in turkey transport boxes.

Turkeys were sexed, classified as either juvenile or adult using ninth and tenth primary feather replacement aging techniques (Pelham and Dickson, 1992) and marked with two metal patagial wing tags (Model 681, National Band and Tag, Newport, Kentucky). Backpack-style radiotransmitters (120 g, expected battery life of $3 \mathrm{y}$; Telemetry Solutions, Walnut Creek, California) with $4 \mathrm{~h}$ mortality sensors were attached to turkeys using elastic shock cord (Wilson and Norman, 1995). Efforts were made to radiomark a similar number of juvenile males, adult males, juvenile females and adult females each year. All birds were released within $3 \mathrm{~h}$ at the capture site. We operated under Purdue University IACUC Protocol 01-080.

A vehicle-mounted null-peak Yagi antenna configuration (Brinkman et al., 2002), equipped with a digital compass and hand-held receiver, was used to record turkey locations and monitor survival. During the agricultural growing season (May-September), all radiomarked turkeys were located 9 times/d during 2 non-consecutive weekdays (chosen arbitrarily), 3 wk per mo, for a total of $6 \mathrm{~d}$ per mo. During the agricultural dormant season (October-April) radiomarked birds were located once per day, 1-2 d per wk. Additionally, all turkeys were monitored for mortality by listening for activity (times chosen arbitrarily) 13 times per wk on days when location data were not being collected.

Mortality events were investigated immediately upon detection of a mortality signal, except during the nesting season when the inactivity of incubating hens often triggered mortality sensors. During the nesting season, investigation of mortality signals for females was delayed $28 \mathrm{~d}$ from the estimated incubation start date. Cause of death for each mortality event was determined using evidence recovered at the site of the carcass and classified as harvest, predation (avian, canid or unknown mammal), unknown, or other (e.g., vehicle, accidental, starvation, disease). When determining cause of death, consideration was given to the presence or absence of head and neck, chew characteristics on bones and feathers, detection of urine, feces, hair or feathers and evidence of caching (Thogmartin and Schaeffer, 2000). Cause of death was assigned to a mortality event only when sufficient evidence was collected to assign a cause confidently. Mortality rates were calculated for each cause of death as percentages of the total mortality. We acknowledge that there are potential biases associated with calculating mortality rates using this technique (Heisey and Fuller, 1985), but with limited sample sizes this is a common reporting technique.

Because of the overall small sample size and limited number of juvenile turkeys $(n=29)$, age specific survival estimates could not be calculated within each sex. Therefore, data for adults and juveniles were pooled for each sex for all survival analyses. Annual and seasonal survival estimates were generated using the staggered entry Kaplan-Meier method modified by Pollock et al. (1989). All mortalities occurring within $7 \mathrm{~d}$ of capture were censored from survival analyses (Vangilder and Sheriff, 1990). Additionally, we censored all turkeys with radio transmitter failure or loss of radio contact on the last day of radio observation.

Annual survival estimates were generated for each sex over the period 1 April through 31 March in 2003-2004 and 2004-2005. Seasonal survival estimates were generated for four, 3 mo periods (i.e., seasons) occurring between 1 April 2003 and 30 June 2005: 1 April-30 June (spring), 1 July-30 September (summer), 1 October-31 December (fall) and 1 January-31 March (winter), resulting in survival estimates for 3 spring, 2 summer, 2 fall and 2 winter seasons. Seasons were chosen to represent temporal patterns of turkey behavior: spring (mating and nesting season and spring hunting season), summer (brood rearing season), fall (large flock establishment) and winter (aggregation on wintering grounds). 
TABLE 1.-Cause-specific mortality [number, (percent)] for radio-marked male and female turkeys in northern Indiana, 2003-2005

\begin{tabular}{lccc}
\hline \hline \multicolumn{1}{c}{ Cause of death } & Male & Female & Total \\
\hline Harvest & $12(46.2)$ & $0(0.0)$ & $12(34.3)$ \\
Canid predation & $3(11.5)$ & $1(11.1)$ & $4(11.4)$ \\
Avian predation & $2(7.7)$ & $1(11.1)$ & $3(8.6)$ \\
Unk. Mammal predation & $2(7.7)$ & $1(11.1)$ & $3(8.6)$ \\
Other & $0(0.0)$ & $1(11.1)$ & $1(2.8)$ \\
Unknown & $7(26.9)$ & $5(55.6)$ & $12(34.3)$ \\
Total & 26 & 9 & 35 \\
\hline
\end{tabular}

Because of sample size limitations, data for seasonal survival estimates were pooled across years for each sex prior to analysis. We acknowledge that pooling data across years may bias survival estimates, but due to sample size limitations it was necessary.

A log-rank test (Pollock et al., 1989) was used to compare annual survival curves for each sex to determine whether temporal patterns of annual survival differed between years within sexes. Program CONTRAST (Sauer and Hines, 1989) was used to test for homogeneity of annual survival estimates within and between sexes using Chi-square tests. We also tested for homogeneity of survival estimates between years within sexes and between sexes within each year, for homogeneity of seasonal survival estimates within and between sexes, and for homogeneity in survival estimates both across seasons within each sex and between sexes within each seasonal period.

\section{RESUlts}

We successfully captured 124 turkeys (52 male, 72 female). Of these, 92 (47 male [25 adult and 22 juvenile] and 45 female [36 adults and 9 juvenile]) were radiomarked. Forty mortalities were recorded during the course of the study. However, five were censored because they likely resulted from trapping or radiomarking efforts. Of the remaining 35 mortalities used for analyses (26 male and 9 female), we determined cause-specific mortality for 23 (Table 1). Overall, predation accounted for $28.6 \%$ of all mortalities. Hunter harvest $(46.2 \%)$ was the leading known cause of mortality for males, followed by predation (26.9\%). Of the four known-caused mortalities for females, predation accounted for three and accidental death (other) accounted for one. Predation by birds and unknown mammals each accounted for $8.6 \%$ of overall mortality for male and female turkeys combined. Seven $(26.9 \%)$ of the 26 mortalities experienced by males and $5(55.6 \%)$ of nine mortalities experienced by females could not be attributed to a specific cause. Three of the five unknown causes of mortality for females occurred during the nesting season when investigation was delayed to prevent disruption of incubation. Only one death of 35 was classified as "other."

Annual survival (Fig. 1) for males was 0.214 ( $\mathrm{sE} \pm 0.085$ ) in 2003-2004 and 0.300 ( $\mathrm{sE} \pm$ 0.102 ) in 2004-2005 (Table 2). Annual survival for females was 0.800 (sE \pm 0.135 ) in 20032004 and 0.755 ( $\mathrm{sE} \pm 0.113$ ) in 2004-2005. Log rank tests for both males and females failed to detect differences in annual survival distributions between years $(P=0.908-0.925 ; P=$ $0.207-0.228$, respectively). Annual survival estimates within sexes were homogeneous between years for both males $\left(\chi^{2}=0.420,1 \mathrm{df}, \mathrm{P}=0.517\right)$ and females $\left(\chi^{2}=0.056,1 \mathrm{df}, \mathrm{P}\right.$ $=0.812)$. However, differences in annual survival estimates were detected between sexes in 2003-2004 $\left(\chi^{2}=13.493,1 \mathrm{df}, \mathrm{P}<0.001\right)$ and 2004-2005 $\left(\chi^{2}=8.934,1 \mathrm{df}, \mathrm{P}<0.003\right)$. 


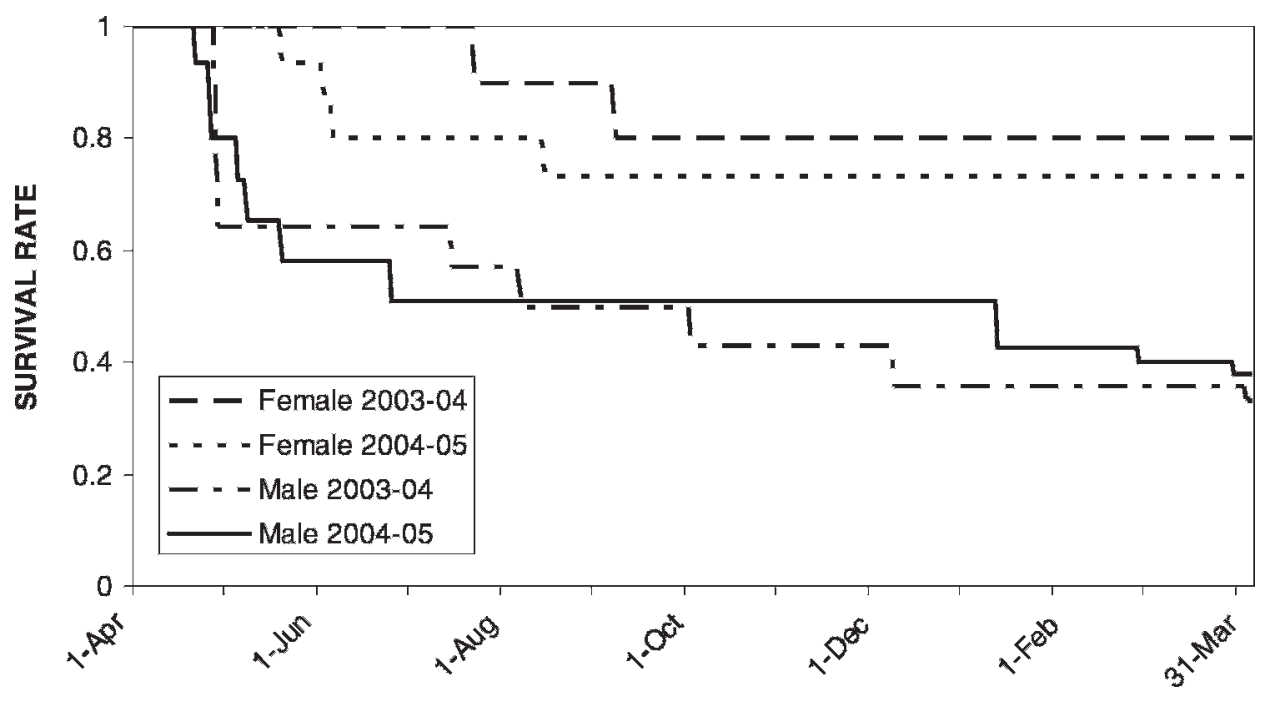

APRIL 1 - M ARCH 31

Fig. 1.-Annual survival distributions for radio-marked male and female turkeys in northern Indiana for 1 April 2003-31 March 2004 and 1 April 2004-31 March 2005

Seasonal survival estimates for male turkeys ranged from 0.673 during the spring to 0.813 during the summer. Seasonal survival estimates for females were less variable than those of males, ranging from 0.864 during summer to 0.934 during the fall. Differences among seasonal survival estimates were not detected for either males or females $\left(\chi^{2}=1.871,3 \mathrm{df}, \mathrm{P}\right.$ $=0.599$ and $\chi^{2}=1.007,3 \mathrm{df}, \mathrm{P}=0.799$, respectively). However, intersexual differences in survival estimates within seasons were detected for the spring, fall and winter seasons $\left(\chi^{2}=\right.$ 13.219, 1 df, $\mathrm{P}<0.001, \chi^{2}=14.010,1 \mathrm{df}, \mathrm{P}<0.001$, and $\chi^{2}=6.965,1 \mathrm{df}, \mathrm{P}=0.008$, respectively). Survival estimates did not differ between sexes during the summer season $\left(\chi^{2}\right.$ $=0.210,1 \mathrm{df}, \mathrm{P}=0.647)$.

\section{Discussion}

Hunting and predation were the top known causes of mortality for male turkeys in northern Indiana, a finding consistent with reports on turkey mortality throughout the Midwest. For example, in Wisconsin (Paisley et al., 1995), Kentucky (Wright and Vangilder, 2000) and Missouri (Vangilder, 1995), legal harvest accounted for 59\%, 54\% and 30\% of known mortality, respectively, whereas predation accounted for $27 \%$, $27 \%$ and $51 \%$, respectively. Unlike most survival studies of male turkeys, our data did not indicate any known mortality due to crippling loss or illegal harvest. In fact, only three male turkey mortalities classified as "unknown" occurred during a period that included the spring turkey season and $30 \mathrm{~d}$ thereafter. Although these unknown mortalities might have been the result of crippling loss or illegal harvest, their relatively small number indicates they were not a major cause of mortality for male turkeys. The lack of such hunting-related effects may have resulted from our limited sample size or high rate of non-hunting recreational use of the state properties (reservoirs) in our study area, which could have deterred poaching. However, crippling loss and illegal harvest can account for relatively 


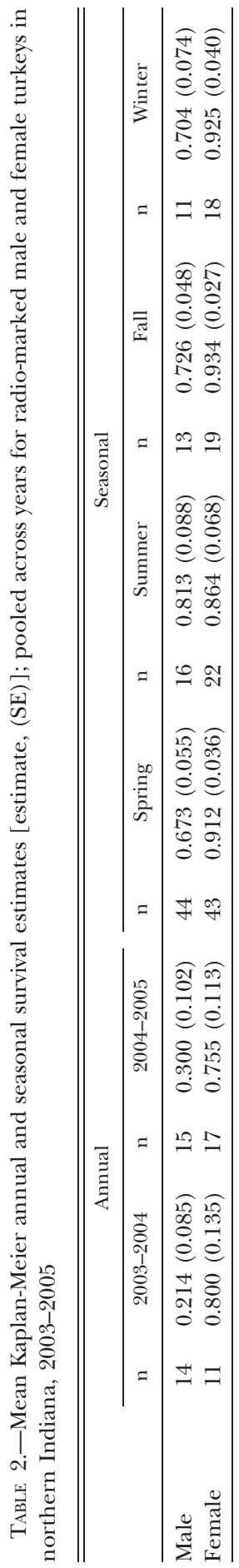


high proportions of total mortality for male (22\%; Vanguilder, 1995) and female turkeys (10\%; Miller et al., 1998). Although no unattributed female mortalities occurred during or after the spring turkey seasons, nesting behavior and deaths associated to that may have masked any illegal take or crippling loss.

Predation $(33.3 \%)$ was the leading known cause of mortality for female turkeys in our study, consistent with findings from numerous other studies of mortality of eastern wild turkey hens throughout the Midwest (Kurzejeski et al., 1987; Vander Haegen et al., 1988; Wright et al., 1996; Miller et al., 1998; Hubbard et al., 1999). However, total female mortality (9 of 43) was low compared to other long-term studies (Vangilder and Kurzejeski, 1995; Wright et al., 1996; Miller et al., 1998). Although, the duration of our study (2.5 y) was short and may not have accounted for the full life span of female turkeys (18 mo, but highly variable; Blankenship, 1992) caught later in the study.

We were conservative when assigning cause of death to mortality events for turkeys monitored in this study. As a result, unknown causes of death accounted for $5(55.6 \%)$ of the 9 recorded mortalities of females and 7 (26.9\%) of 26 recorded mortalities of males. The high proportion of mortality events for which a cause could not be ascribed was likely the result of scavenging activities, which may have delayed onset of mortality signals until carcasses were completely consumed or displaced from their transmitters. Raccoon (Procyon lotor) and Virginia opossum (Didelphis virginiana) were ubiquitous throughout the study area (Beasley, 2005; Beasley and Rhodes, 2008), and such species are very capable scavengers (DeVault et al., 2004). Thus, non-predator mortalities (disease, vehicle-related, illegal take, etc.) may have been underestimated due to interference of scavenging activity with timing of mortality signals. Furthermore, mortality checks were performed 2-4 times per wk, resulting in possible 1-3 d lapses in known fate, especially during fall and winter seasons.

Annual survival estimates for male turkeys in our study were among the lowest recorded for males of this species. Only Little et al. (1990) in Iowa, reported lower annual survival estimates for male turkeys (28\% for adults and $17 \%$ for juveniles). However, their estimates included mortality associated with fall hunting, which was illegal in our population. Male survival estimates in Kentucky (26\% adult and 55\% juvenile; Wright and Vangilder, 2000), Mississippi (41\% pooled ages; Godwin et al., 1991), Wisconsin (51\% pooled ages; Paisley et al., 1995) and Minnesota (64\% pooled ages; Porter, 1978) highlight the wide range of annual survival estimates that wild turkey populations can exhibit, given age of the population and amount of hunter effort. Low annual survival of males in our study likely reflected predation throughout the year coupled with hunting mortality. Hunting pressure on public lands in our study area was constant throughout the season. Groups of lottery drawn hunters were allowed hunting access to public land portions of our study area, with new groups of hunters $(\sim 40)$ allowed access every 2-3 d throughout the 19-d hunting season. Unfortunately, no data exist for hunting pressure on private lands, but it is generally accepted that private lands receive less hunting pressure than publicly accessible lands.

Conversely, annual survival estimates for hen turkeys in our study were among the highest reported for females of this species. Estimates of hen survival for turkeys from Missouri (0.435 pooled ages; Kurzejeski et al., 1987), New York (0.498 pooled ages; Roberts et al., 1995), Wisconsin (0.527 pooled ages; Wright et al., 1996), Iowa (0.676 adult and 0.713 juvenile; Hubbard et al., 1999) and Mississippi (0.508 adult; Miller et al., 1998) represent more typical survival rates for hens. The unusually high annual survival estimates for females in our study may have resulted from their atypically high spring survival.

Seasonal survival estimates for males in our study varied markedly, from 0.673 during spring to 0.813 during summer. Unexpectedly, spring survival estimates for males did not 
differ significantly from those of the three other seasons. By comparison, seasonal survival estimates reported for male turkeys in many other studies consistently have been lowest during the spring hunting season (Vangilder, 1995; Paisley et al., 1995; Wright and Vangilder, 2000). In Kentucky (Wright and Vangilder, 2000; average spring survival not reported) and Wisconsin (Paisley et al., 1995; average spring survival $=0.642$ ) seasonal survival estimates of males outside the spring hunting season were $\geq 80 \%$ and $\geq 90 \%$, respectively, and in Mississippi only $9 \%$ of all gobbler mortality occurred outside the spring hunting season (Godwin et al., 1991). Although low seasonal survival of males outside the spring hunting season is not unexpected, especially for northern populations, it is often related to weather variables such as deep snow cover (Wunz and Hayden, 1975; Porter, 1978), which was rare in our study area. Even though wounding loss and poaching were not documented as known causes of mortality, further investigation into these factors may shed light onto the unusually low male seasonal survival rates observed.

Seasonal survival rates of females were homogenous, ranging from 0.864 during summer to 0.934 during fall. Other studies have found female survival to be lowest during spring (Kurzejeski et al., 1987; Vander Haegen et al., 1988; Palmer et al., 1993; Roberts et al., 1995; Vangilder and Kurzejeski, 1995; Wright et al., 1996). However, the spring survival estimate for hens in our study is one of the highest spring survival estimates for hen turkeys ever reported. The high spring survival of hens in our study may have resulted from nest loss which prevented hens from incubating, thus hens spent less time incubating and brood rearing. Other studies have documented similar survival patterns due to low nesting success (Miller et al., 1998; Wilson et al., 2005). Observations of hen flocks during summer and fall seasons without broods and evidence of high nest loss (86\% nest loss for marked females initiating incubation) indicated low recruitment. Winter trapping efforts, which revealed low numbers of juvenile birds, corroborated evidence of low recruitment rates.

Although sources of cause-specific mortality for both male and female turkeys in northern Indiana appear to be similar to those observed in other midwestern states, the unusually low annual survival estimates for males may warrant concern. In small, isolated populations such as those found in the fragmented landscape of northern Indiana, male hunting mortality may be additive (Godwin et al., 1991) and thus, detrimental to population sustainability. Because biologists and managers are constantly pressured to provide maximum hunting opportunities, it is essential that they quantify factors such as gobbler survival and causespecific mortality so populations can persist in the context of regulated harvest. Although studies by Suchy et al. (1990), Roberts et al. (1995) and Hubbard et al. (1999) suggest that productivity may have a greater effect on population persistence than adult survival, these studies were conducted on large, well established populations. Consequently, mortality might have a greater impact on population dynamics of small, isolated populations, especially if recruitment also is low.

Balancing impacts of predators and hunters on turkey population viability involves complex and sometimes difficult policy decisions (Healy and Powell, 2000). Vangilder and Kurzejeski (1995) demonstrated that generous spring harvest of males, in addition to other forms of mortality, can limit the number of adult males present the following spring. Healy and Powell (2000) recommended regulating hunter densities, as opposed to adjusting season length or timing, to better control impacts of harvest on population size. Because biologists have greater immediate control over harvest regulations than on predator densities or habitat management, reducing hunting pressure through the lottery permit system could be an effective tool to manage male turkey populations on public lands in 
northern Indiana. Additionally, public and private landowners should strive to provide adequate nesting habitat in the hopes of increasing nest success.

Acknowledgments.-This study would not have been possible without cooperation of numerous landowners who allowed us access to their land. We thank J. Beasley and the many research technicians for their assistance in data collection. Thanks to the numerous state biologists and conservation officers from Indiana for their assistance in trapping and with public relations. S. Backs, H. P. Weeks and B. E. Washburn provided editorial comments in the writing of this manuscript. Funding was provided by the Indiana Department of Natural Resources, the National Wild Turkey Federation, the Indiana Chapter of the National Wild Turkey Federation and Purdue University.

\section{Literature Cited}

Backs, S. E. 1995. Twenty-five years of turkey hunting in Indiana. Proc. of the $7^{\text {th }}$ Nat. Wild Turkey Symp., $7: 245-252$.

Bailey, W., D. Dennett, Jr., H. Gore, J. Pack, R. Simpson and G. Wright. 1980. Basic considerations and general recommendations for trapping the wild turkey. Proc. of the $4^{\text {th }}$ Nat. Wild Turkey Symp., 4:10-23.

Baumann, D. P., JR., L. D. Vangilder, C. I. Taylor, R. Engle-Wilson, R. O. Kimmel and G. A. Wunz. 1990. Expenditures for wild turkey hunting. Proc. of the $6^{\text {th }}$ Nat. Wild Turkey Symp., 6:157-166.

Beasley, J. C. 2005. Habitat use and movement behavior of raccoons (Procyon lotor) in an agriculturally fragmented landscape. Thesis. Purdue University, West Lafayette, Indiana.

— AND O. E. Rhodes, JR. 2008. Relationship between raccoon abundance and crop damage. Hum. Wldlf. Confl., in press.

Blankenship, L. H. 1992. Physiology, p. 84-100. In: J. G. Dickson (ed.). The wild turkey: biology and management. Stackpole Books, Harrisburg, Pennsylvania.

Brinkman, T. J., C. S. Deperno, J. A. Jenks, J. D. Erb and B. S. Haroldson. 2002. A vehicle-mounted radio telemetry antenna system design. Wldlf. Soc. Bull., 30:258-262.

Devault, T. L., I. L. Brisbin, JR. AND O. E. Rhodes, Jr. 2004. Factors influencing the acquisition of rodent carrion by vertebrate scavengers and decomposers. Can. J. of Zool., 82:502-509.

Godwin, K. D., G. A. Hurst ANd R. L. Kelley. 1991. Survival rates of radio-equipped wild turkey gobblers in east-central Mississippi. Proc. of the Ann. Conf. of Southeast Assoc. of Fish and Wldlf. Agen., 45:218-226.

Healy, W. M. and S. M. Powell. 2000. Wild turkey harvest management: planning for the future. Proc. of the $8^{\text {th }}$ Nat. Wild Turkey Symp., 8:233-241.

Heisey, D. M. AND T. K. Fuller. 1985. Evaluation of survival and cause-specific mortality rates using telemetry data. J. of Wldlf. Manag., 49:668-674.

Hubbard, M. W., D. L. Garner and E. E. KlaAs. 1999. Factors influencing wild turkey hen survival in southcentral Iowa. J. of Wldlf. Manag., 63:731-738.

Keck, R. and J. Langston. 1992. Recreational use, p. 388-407. In: J. G. Dickson (ed.). The wild turkey: biology and management. Stackpole Books, Harrisburg, Pennsylvania.

Kennamer, J. E. And M. C. Kennamer. 1995. Status and distribution of the wild turkey in 1994. Proc. of the $7^{\text {th }}$ Nat. Wild Turkey Symp., 7:203-212.

Kurzejeski, E. W., L. D. Vangilder and J. B. Lewis. 1987. Survival of wild turkey hens in north Missouri. J. of Wldlf. Manag., 51:188-193.

Little, T. W., J. M. Kienzler and G. A. Hanson. 1990. Effects of fall either sex hunting on survival of an Iowa wild turkey population. Proc. of the $6^{\text {th }}$ Nat. Wild Turkey Symp., 6:119-125.

Miller, D. A., L. W. Burger, B. D. Leopold and G. A. Hurst. 1998. Survival and cause-specific mortality of wild turkey hens in central Mississippi. J. of Wldlf. Manag., 62:306-313.

Moore, J. E. And R. K. Swihart. 2005. Modeling patch occupancy by forest rodents: incorporating detectability and spatial autocorrelation with hierarchically structured data. J. of Wldlf. Manag., 69:933-949.

NOAA National Weather Service. 2005. Northern Indiana: Fort Wayne Indiana Climate. http://www. crh.noaa.gov/iwx/CLI/FWA/history/climatedescription.php. 
Paisley, R. N., R. G. Wright and J. F. Kubisiak. 1995. Survival of wild turkey gobblers in southwestern Wisconsin. Proc. of the $7^{\text {th }}$ Nat. Wild Turkey Symp., 7:39-44.

Palmer, W. E., S. R. Priest, R. S. Seiss, P. S. Phalen and G. A. Hurst. 1993. Reproductive effort and success in a declining Wild Turkey population. Proc. of the Ann. Conf. of Southeastern Fish and Wldlf. Agen., 47:138-147.

Pelham, P. H. and J. G. Dickson. 1992. Physical characteristics, p. 32-45. In: J. G. Dickson (ed.). The wild turkey: biology and management. Stackpole Books, Harrisburg, Pennsylvania.

Pollock, K. H., S. R. Winterstein, C. M. Bunck and P. D. Curtis. 1989. Survival analysis in telemetry studies: the staggered entry design. J. of Wldlf. Manag., 53:7-15.

Plowman, B. W. 2004. March 2004 raccoon road-kill survey. Indiana Department of Natural Resources, Report 868.

2006. 2005 Statewide archers index of furbearer populations. Indiana Department of Natural Resources, Report 915.

Porter, W. F. 1978. The ecology and behavior of the wild turkey (Meleagris gallopavo) in south-eastern Minnesota. Dissertation. University of Minnesota, Minneapolis.

Roberts, S. D., J. M. Coffee and W. F. Porter. 1995. Survival and reproduction of female wild turkeys in New York. J. of Wldlf. Manag., 59:237-447.

SAuER, J. R. AND J. E. Hines. 1989. Testing for differences among survival or recovery rates using program CONTRAST. Wldlf. Soc. Bull., 17:549-550.

Suchy, W. J., G. A. Hanson and T. W. Little. 1990. Evaluation of a population model as a management tool in Iowa. Proc. of the $6^{\text {th }}$ Nat. Wild Turkey Symp., 6:196-204.

SwiHart, R. K. and N. A. SLAdE. 2004. Modeling interactions of private ownership and biological diversity: an architecture for landscapes with sharp edges, p. 3-21. In: R. K. Swihart and J. E. Moore (eds.). Conserving biodiversity in agricultural landscapes: model-based planning tools. Purdue University Press, West Lafayette, Indiana.

Tapley, J. L., W. M. Healy, R. K. Abernethy and J. E. Kennamer. 2000. Status of turkey hunting in North America. Proc. of the $8^{\text {th }}$ Nat. Wild Turkey Symp., 8:257-267.

Thogmartin, W. E. And B. A. Schaeffer. 2000. Landscape attributes associated with mortality events of wild turkeys in Arkansas. Wldlf. Soc. Bull., 28:865-874.

U.S. Census Bureau. 2000. Population and housing unit counts. PHC-3-1. Table 20.

Vander Haegen, W. M., W. E. Dodge and M. W. Sabre. 1988. Factors affecting productivity in a northern wild turkey population. J. of Wldlf. Manag., 52:127-133.

VAngilder, L. D. 1995. Survival and cause specific mortality of wild turkeys in the Missouri Ozarks. Proc. of the $7^{\text {th }}$ Nat. Wild Turkey Symp., 7:21-32.

AND E. W. Kurzejeski. 1995. Population ecology of the eastern wild turkey in northern Missouri. Wldlf. Monog., 130:1-50.

AND S. L. Sheriff. 1990. Survival estimation when fates of some mammals are unknown. Trans., Missouri Acad. of Sci., 24:57-65.

Wilson, T. S. and G. W. Norman. 1995. Techniques and materials used in attaching radio-transmitters to wild turkeys. Proc. of the $7^{\text {th }}$ Nat. Wild Turkey Symp., 7:115-122.

Wilson, W. B., M. J. Chamberlain and F. G. Kimmel. 2005. Survival and nest success of female wild turkeys in a Louisiana bottomland hardwood forest. Proc. of the Ann. Conf. of the Southeastern Assoc. of Fish and Wldlf. Agen., 59:126-134.

Wright, R. G., R. N. Paisley and J. F. Kubisiak. 1996. Survival of wild turkey hens in southwestern Wisconsin. J. of Wldlf. Manag., 60:313-320.

AND L. D. VANGILDER. 2000. Survival of eastern wild turkey males in western Kentucky. Proc. of the $8^{\text {th }}$ Nat. Wild Turkey Symp., 8:187-194.

Wunz, G. A. AND A. H. Hayden. 1975. Winter mortality and supplemental feeding of turkeys in Pennsylvania. Proc. of the $3^{\text {rd }}$ Nat. Wild Turkey Symp., 3:61-69. 